\title{
SISTEM MONITORING ANGKRINGAN BERBASIS ANDROID UNTUK KONSINYASI BARANG
}

\author{
Fernanda Hendra Priyono', ${ }^{1}$ Arief Susanto², Muhammad Malik Hakim ${ }^{3}$ \\ ${ }^{1,2}$ Program Studi Teknik Informatika, Universitas Muria Kudus \\ ${ }^{2}$ Departemen Informatika, Universitas Diponegoro \\ Email: 1'nandahendra123@gmail.com,2ªrief.susanto@umk.ac.id, 3malik@live.undip.ac.id
}

(Naskah masuk: 5 Maret 2021, diterima untuk diterbitkan: 22 Mei 2021)

\begin{abstract}
Abstrak
Angkringan merupakan sebuah tempat berjualan makanan keliling yang dipikul serta pada umumnya berbentuk melengkung ke atas yang biasa terdapat di berbagai jalan di Indonesia. Namun saat ini angkringan berubah model menjadi seperti warung yang berjualan menetap di suatu tempat agar mudah dikenal pelanggannya. Sistem pencatatan dan pendataan barang bagi pemasok angkringan diperlukan untuk mengetahui manajemen rantai pasok pada angkringan mitra usahanya. Pemasok angkringan dapat melakukan pengaturan data angkringan, data barang, data penitipan, data penarikan, dan terdapat fasilitas untuk mengetahui detail laporan penjualan dari masing-masing angkringan. Sistem pencatatan dan monitoring angkringan ini dibangun menggunakan aplikasi Android Studio dengan menggunakan metode waterfall dan mendukung LBS (Location Based Service) sebagai titik pemetaan tempat angkringan yang ingin dituju serta GPS (Global Positioning System) untuk mengetahui detail lokasi dan alamat angkringan mitra. Berdasarkan studi awal, penelitian, perancangan, pembuatan dan pengujian sistem monitoring angkringan, pelaku usaha yang merupakan pemasok angkringan dapat melakukan manajemen rantai pasok barang jualannya ke angkringan-angkringan yang menjadi mitranya dengan mudah serta dapat mengetahui rincian pelaporan dari hasil penjualan setiap angkringan yang menjadi mitra usahanya.
\end{abstract}

Kata kunci: angkringan, rantai pasok, monitoring, LBS, GPS

\section{ANDROID BASED ANGKRINGAN MONITORING SYSTEM FOR GOODS CONSIGNATION}

\begin{abstract}
Angkringan is a place for selling traditional food that is carried and curved upward, which is commonly seen on various roads in Indonesia. However, angkringan recently changed its model like a stall that stay permanently in a place so that their customers can easily recognize and remember its location. A system of recording and data collection of goods from angkringan suppliers is needed to know the supply chain management of their angkringan business partners. Angkringan providers can manage angkringan's data, namely goods, deposit, expiry date, and there are facilities to find out detailed sales reports for each angkringan. This angkringan recording and monitoring system was built using the Android Studio application using the waterfall method and supports LBS (Location Based Service) as a mapping point for the place of angkringan and GPS (Global Positioning System) to find out the details location, map, and address of the angkringan partner. Based on preliminary studies, research, design, implementation and testing of the angkringan monitoring system, angkringan supplier businesses can easily manage the supply chain of their selling goods to many angkringan partner and can find out detailed sales results reporting from each of them.
\end{abstract}

Keywords: angkringan, supply chain, monitoring, LBS, GPS 


\section{PENDAHULUAN}

Indonesia merupakan negara kepulauan dengan wilayah yang sangat luas, dimana banyak sekali ditemui penduduk yang mendirikan toko atau usaha berbentuk UMKM. Hampir di setiap desa dan kecamatan di semua daerah kota / kabupaten memiliki banyak sekali jenis umkm dengan aneka ragam jenis dan bentuk usahanya, mulai dari fashion, kerajinan, kuliner, dan sebagainya.

Selama masa pandemi yang dimulai sejak tahun 2020, banyak masyarakat yang telah kehilangan pekerjaan maupun usaha sebagai dampak dari pandemik. Namun, ada satu jenis usaha yang sepertinya tidak begitu terpengaruh, yaitu usaha konsinyasi makanan. Semakin banyaknya pelaku usaha konsinyasi makanan selama masa pandemi, diperlukan sebuah aplikasi dimana orang dapat membangun usaha nya sendiri dan selanjutnya dapat melakukan pengelolaan usahanya dengan mudah dan efisien.

Konsinyasi adalah suatu bentuk kerjasama dalam penjualan produk yang dilakukan oleh pemilik barang dengan penyalur, pedagang, atau pemilik toko. Dalam sistem kerjasama penjualan ini, pemilik barang menitipkan barang dagangannya kepada penyalur, pedagang, atau pemilik toko, warung atau angkringan untuk dijual. Sederhananya, konsinyasi dipahami sebagai jual titip. Namun usaha konsinyasi tersebut harus diikuti dengan manajemen data dan informasi yang tepat dan akurat karena secara sederhana harus dapat menghitung dan memberikan pelaporan berupa total barang yang dititipkan di masing-masing angkringan dan realisasi hasil penjualan untuk pengambilan keputusan apakah toko, warung atau angkringan tersebut harus di tambah barang nya atau malah dikurangi ataupun di stop penitipan.

Untuk mengatasi masalah tersebut perlu dibuat aplikasi sistem informasi monitoring angkringan untuk konsinyasi barang yang berguna bagi pemilik usaha konsinyasi untuk melakukan monitoring data penjualan barang yang di titipkan di toko maupun angkringan beserta melakukan monitoring terhadap para pekerja yang sedang melakukan penitipan barang nya di toko maupun angkringan. Sistem monitoring ini menggunakan GIS (Geografi Informasi Sistem) serta menggunakan Metode LBS (Location Based Sistem) dan GPS (Global Position System).

\section{PENELITIAN TERKAIT}

Pada umumnya, sistem monitoring dikembangkan untuk melakukan pemantauan dari jarak jauh. Sistem monitoring model seperti ini dikembangkan karena pemantauan secara langsung dari jarak dekat tidak memungkinkan, misalnya diterapkan pada monitoring rumah menggunakan webcam (Husni, Ijtihadie, \& Bisaptanto, 2005) dan internet (Prihatmoko, 2018)) atau sangat berbahaya seperti monitoring terjadinya kebakaran hutan (Prasetyo, 2013).

Pengembangan sistem monitoring juga dilakukan untuk memantau serangkaian proses. Hal ini dilakukan karena pemantauan secara terus menerus perlu dilakukan untuk memastikan suatu proses berjalan dengan baik atau sesuai harapan. Sistem monitoring seperti ini sering dikembangkan di lingkungan perguruan tinggi, antara lain untuk melakukan monitoring dan evaluasi pengelolaan program studi, (Wijaya, 2018), monitoring proses belajar mengajar (Somya, Suprohadi, \& Prasetyo, 2018), presensi mahasiswa dalam mengikuti perkuliahan secara online (Rahmat dan Yunanto, 2017), serta kinerja dosen (Salamun dan Arisandi, 2020) dan perkembangan skripsi (Monalisa dan Kurniadi, 2019). Adapun di luar perguruan tinggi, sistem monitoring dapat dilakukan pada bidang kesehatan misalnya monitoring tumbuh kembang anak di Posyandu (Sardi, Habibullah, dan Risfendra, 2019).

Sistem moitoring dapat dikembangkan dengan berbagai model, misalnya menggunakan LBS untuk mengkonfirmasi dan melakukan pemetaan posisi lokasi secara akurat dan menggunakan GIS untuk mengetahui data alamat secara tepat. Misalnya dilakukan untuk pengelolaan persebaran aset wakaf berbasis GIS (Fahmi dan Sugiarto, 2016), dan monitoring pengisian LPG menggunakan LBS (Arta, Siswanto, dan Setiawan, 2018).

\section{METODE PENELITIAN}

\subsection{Pengembangan Sistem Waterfall}

Metode Waterfall adalah metode yang menyarankan pendekatan yang sistematis dan sekuensiaal melalui tahapan-tahapan yang ada pada SDLC untuk membantun sebuah perangkat lunak.

Berikut adalah tahap-tahap penjelasan yang ada pada metode Waterfall :

1. Requirement Analisis, pada tahap ini dilakukan untuk mengetahui batasan dan tujuan sistem yang didirikan dengan melakukan konsultasi dengan pengguna sistem, kemudian didefinisikan secara rinci dan berfungsi sebagai spesifikasi sistem.

2. System Design, yaitu tahapan dimana developer atau pengembang sistem melakukan sebuah perancangan dari semua kebutuhan yang sudah ditetapkan dan dicatat pada tahapan sebelumnya.

3. Implementation, pada tahap ini perancangan perangkat lunak direalisasikan sebagai seperangkat program atau unit program. Pengujian unit melibatkan verifikasi bahwa setiap unit sudah memenuhi spesifikasi yang dibutuhkan. 
4. Integration \& Testing, yaitu tahapan dimana unit yang sudah sibuat pada tahapan sebelumnya disatukan menjadi sebuah program yang utuh kemudian diuji apakah sudah sesuai dengan spesifikasi kebutuhan yang sudah ditetapkan.

Operation \& Maintenance, yaitu tahapan terakhir dimana sistem diterapkan dan mulai dipakai. Pada tahap ini dilakukan juga pemeliharaan sistem seperti perbaikan error yang tidak ditemukan pada tahapan sebelumnya. Pada tahap ini pula biasanya terdapat penambahan fitur-fitur baru pada sistem.

\subsection{Metode Pengumpulan Data}

Metode pengumpulan data yang digunakan untuk memperoleh suatu informasi yang diperlukan untuk mencapai suatu penelitian. Berikut adalah metode pengumpulan data :

\section{Observasi}

Observasi merupakan salah satu metode pengumpulan data dimana dalam suatu prose yang diawali dengan pengamatan yang bersifat sistemaris, logis, objektif dan rasional terhadap macam fenomena dalam situasi yang sebenarnya, maupun situasi buatan. Dalam pengumpulan data untuk aplikasi ini adalah dengan mangamati dan mencermati tahapan dari angkringan.

\section{Wawancara}

Wawancara merupakan salah satu metode pengumpulan data dimana dalam suatu proses yang di awali dengen tanya jawab antara narasumber dan wawancara dengen tujuan untuk memperoleh informasi-informasi penting yang nantinya akan di implementasikan dalam aplikasi yang akan di buat. Dalam wawancara ini saya berkesempatan untuk mewawancarai salah satu angkringan dan bertanya hal-hal penting apa saja yang dilakukan ketika proses konsinyasi barang.

\section{Studi Pustaka}

Studi Pustaka merupakan salah satu metode pengumpulan data dengan mempelajari dari jurnal maupun menggunakan internet yang berkaitan dengan alur, informasi, maupun metode-metode yang berguna untuk pembuatan aplikasi yang sedang di kerjakan.

\section{HASIL DAN PEMBAHASAN}

Hasil dari sistem monitoring angkringan untuk konsinyasi barang berbasis android adalah sebuah data penitipan dan penarikan dan data hasil bagi untuk pihak angkringan berikut adalah hasil dari sistem :

\subsection{Implementasi Sistem}

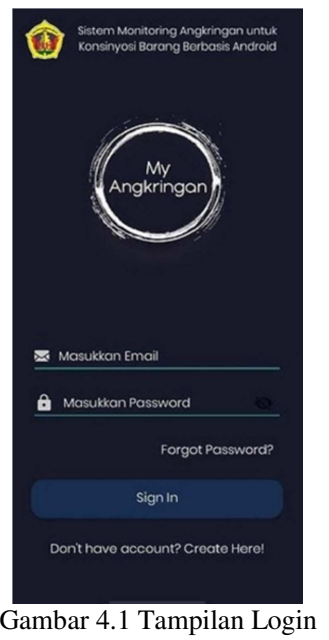

Pada tampilan diatas ini user akan login sebagai admin atau konsinyi.

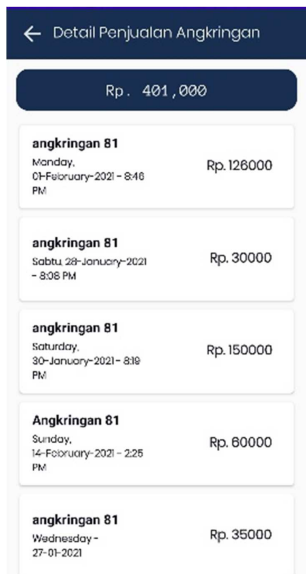

Gambar 4.2 Tampilan Detail Penjualan Angkringan

Pada tampilan diatas merupakan hasil dari data penitipan barang ke angkringan oleh admin.

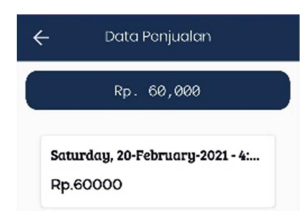

Gambar 4.3 Tampilan Data Penjualan

Pada tampilan diatas merupakan hasil bagi pada pihak angkringan oleh konsinyi. 


\subsection{Black Box Testing}

Pengujian menggunakan Black-box dilakukan untuk menguji fungsi-fungsi yang terdapat pada sistem, Black-box juga digunakan untuk mendefinisikan kumpulan konsisi input dan menguji spesifikasi fungsionalitas program. Berikut hasil pengujian sistem yang telah di bangun menggunakan Black-box :

\begin{tabular}{|c|c|c|c|c|}
\hline No & $\begin{array}{l}\text { Aktivitas } \\
\text { Pengujian }\end{array}$ & $\begin{array}{l}\text { Hasil yang } \\
\text { diharapkan }\end{array}$ & $\begin{array}{l}\text { Hasil } \\
\text { Uji }\end{array}$ & Kesimpulan \\
\hline 1 & $\begin{array}{l}\text { Memasukkan } \\
\text { email dan } \\
\text { password } \\
\text { (admin) lalu } \\
\text { tekan tombol } \\
\text { login }\end{array}$ & $\begin{array}{l}\text { Masuk ke } \\
\text { halaman } \\
\text { utama admin }\end{array}$ & Sesuai & Berhasil \\
\hline 2 & $\begin{array}{l}\text { Memasukkan } \\
\text { email dan } \\
\text { password } \\
\text { (konsinyi) lalu } \\
\text { tekan tombol } \\
\text { login }\end{array}$ & $\begin{array}{l}\text { Masuk ke } \\
\text { halaman } \\
\text { utama } \\
\text { konsinyi }\end{array}$ & Sesuai & Berhasil \\
\hline
\end{tabular}

\begin{tabular}{lllll}
\multicolumn{5}{c}{ Tabel 4.2 Black Box Testing Penjualan } \\
\hline No & $\begin{array}{l}\text { Aktivitas } \\
\text { Pengujian }\end{array}$ & $\begin{array}{l}\text { Hasil yang } \\
\text { diharapkan }\end{array}$ & $\begin{array}{l}\text { Hasil } \\
\text { Uji }\end{array}$ & Kesimpulan \\
\hline 1 & Pada list & Sistem & & \\
data & menampilkan & & \\
& penjualan & detail data & Sesuai & Berhasil \\
& lalu klik & penjualan & & \\
salah salah & & & \\
& satu list & & & \\
\end{tabular}

Tabel 4.3 Black Box Testing Data Penitipan

\begin{tabular}{lllll}
\hline No & $\begin{array}{l}\text { Aktivitas } \\
\text { Pengujian }\end{array}$ & $\begin{array}{l}\text { Hasil yang } \\
\text { diharapkan }\end{array}$ & $\begin{array}{l}\text { Hasil } \\
\text { Uji }\end{array}$ & Kesimpulan \\
\hline 1 & Pilih list & Sistem masuk & & \\
& barang & ke halaman & & \\
& yang ingin & tambah ketika & & \\
& di titipkan, & susah memilih & & \\
& lalu masuk & list barang, & & \\
& ke halaman & lalu sistem & Sesuai & Berhasil \\
& tambah & menambahkan & & \\
& angkringan, & data penitipan & & \\
& mengisi & ke database. & & \\
& form, lalu & & & \\
& tekan titip & & & \\
& barang & & & \\
\hline
\end{tabular}

Tabel 4.4 Black Box Testing Data Penarikan

\begin{tabular}{|c|c|c|c|c|}
\hline No & $\begin{array}{l}\text { Aktivitas } \\
\text { Pengujian }\end{array}$ & $\begin{array}{l}\text { Hasil yang } \\
\text { diharapkan }\end{array}$ & $\begin{array}{l}\text { Hasil } \\
\text { Uji }\end{array}$ & Kesimpulan \\
\hline 1 & $\begin{array}{l}\text { Pilih list } \\
\text { penitipan } \\
\text { yang ingin } \\
\text { dilanjutkan } \\
\text { proses } \\
\text { penarikan, } \\
\text { lalu masuk } \\
\text { ke halaman } \\
\text { tambah } \\
\text { penarikan, } \\
\text { mengisi } \\
\text { form, lalu } \\
\text { tekan tarik } \\
\text { barang }\end{array}$ & $\begin{array}{l}\text { Sistem masuk } \\
\text { ke halaman } \\
\text { tambah ketika } \\
\text { susah memilih } \\
\text { list barang, } \\
\text { lalu sistem } \\
\text { menambahkan } \\
\text { data penitipan } \\
\text { ke database. }\end{array}$ & Sesuai & Berhasil \\
\hline
\end{tabular}

\section{KESIMPULAN DAN SARAN}

Berdasarkan hasil Analisa, perancangan, serta implementasi pada sistem monitoring angkringan untuk konsinyasi barang berbasis android, diperoleh kesimpulan bahwa sistem yang dirancang dan dibangun mampu mengolah data angkringan, karyawan, barang, penitipan dan penarikan, dapat mengurangi penggunaan kertas karena sistem sudah ada aplikasi mobile sehingga praktik untuk di bawa dan lebih efekter serta ramah lingkungan serta memudahkan para supplier umkm atau pengusaha bisnis untuk melakukan penitipan kepada angkringan sehingga dapat membantu ekonomi masyarakat indonesia

Selanjutnya, untuk memastikan perbaikan sistem ke depan agar lebih optimal perlu dibuatkan jadwal untuk karyawan yang ingin menitipkan atau penarikan barang sehingga jadwal lebih terstuktur, pengembangan record maps sehingga admin mengetahui apa saja yang telah dilakukan karyawan pada proses penitipan barang, serta perlu adanya notifikasi yang merupakan reminder bagi pihak pemilik angkringan agar ketika tingkat penjualan lebih tinggi dari perkiraan, admin dapat segera mengetahui untuk segera melakukan re-stok kembali.

\section{DAFTAR PUSTAKA}

ARTA, Y., SISWANTO, A., dan SETIAWAN, A. Sistem Pelayanan dan Monitoring Pengisian LPG Berbasis Mobile pada PT. XYZ, Digital Zone: Jurnal Teknologi Informasi dan Komunikasi, [e-journal] 9(2), pp.106-117. Tersedia di: <https://doi.org/10.31849/digitalzone.v9i2. 1668>

FAHMI, A., SUGIARTO, E., 2016. Sistem Informasi Geografi untuk Pengelolaan dan Monitoring Persebaran Aset Wakaf. Techno.com, [e-journal] pp. 15-4. Tersedia di:

<https://doi.org/10.33633/tc.v15i4.1272>

[Diakses 1 April 2021]

HUSNI, M., IJTIHADIE, R. M., dan BISAPTANTO, J., 2005. Prototype System Monitoring Rumah Menggunakan Webcam. Jurnal Ilmiah Teknologi Informasi, [e-journal] 4(2), pp. 105-111. Tersedia di: < http://juti.if.its.ac.id/index.php/juti/article/vi ew/253> [Diakses 1 April 2021]

MONALISA, S. KURNIADI, B. 2019. Sistem Monitoring Perkembangan Skripsi dengan Reminder System untuk Mahasiswa. Digital Zone: Jurnal Teknologi Informasi dan Komunikasi, [e-journal] 10 (1), pp. 23$32 . \quad$ Tersedia di: <https://journal.unilak.ac.id/index.php/dz/ar ticle/view/2340> [Diakses 1 April 2021] 
PRASETYO, D. W., 2013. Sistem Informasi Geografis Monitoring Persebaran Titik Api di Indragiri Hilir. Sistemasi: Jurnal Sistem Informasi, [e-journal] 2(2), pp. 15-22. Tersedia di: <https://doi.org/10.32520/stmsi.v2i2.164> [Diakses 1 April 2021]

PRIHATMOKO, D., 2018. Perancangan Sistem Monitoring Perangkat Elektronis Rumah Menggunakan Internet. SIMETRIS: Jurnal Teknik Mesin, Elektro, dan Ilmu Komputer, [e-journal] 9(1), pp. 279-286. Tersedia melalui:

https://doi.org/10.24176/simet.v9i1.2041> [Diakses 1 April 2021]

RAHMAT, R. I., YUNANTO, P., W., 2017. Perancangan Dan Pengembangan Aplikasi Sistem Informasi Monitoring Perkuliahan Dan Kehadiran Mahasiswa Berbasis Web. PINTER: Jurnal Pendidikan Teknik Informatika dan Komputer, [e-journal] 1(1), pp. 39-50. Tersedia di: <https://doi.org/10.21009/pinter.1.1.6> [Diakses 1 April 2021]

SALAMUN, S., ARISANDI, D., 2020. Sistem Monitoring Kinerja Dosen Pada Institusi Perguruan Tinggi Swasta (Studi Kasus: Universitas Abdurrab). Digital Zone: Jurnal Teknologi Informasi dan Komunikasi, [e-journal] 11(2), pp. 196-205. Tersedia di: $<$ https://doi.org/10.31849/digitalzone.v11i2 .4304> [Diakses 1 April 2021]

SARDI, J., HABIBULLAH, H., RISFENDRA, R., 2019. Rancang Bangun Sistem Monitoring Pertumbuhan Berat dan Tinggi Anak Balita Berbasis Data pada Posyandu. 2019. [ejournal] 11(2), pp. 53-59. Tersedia di: <https://jurnal.untan.ac.id/index.php/Elkha/ article/view/31141>, [Diakses 1 April 2021]

SOMYA, R., SUPRIHADI, S., PRASETYO, L. B., 2018. Sistem Monitoring Nilai Proses Belajar Mengajar pada Program Studi Menggunakan Web Service. Jurnal Ilmiah Dinamika Rekayasa. 14(1), pp. 1-8. Tersedia di: http://dinarek.unsoed.ac.id/jurnal/index.php /dinarek/article/view/187> [Diakses 1 April 2021]

WIJAYA, C. A., 2018. Sistem Monitoring dan Evaluasi Pengelolaan Program Studi di Institusi Pendidikan Tinggi. Indonesian Journal of Information Systems, 1(1), pp. 13-24. Tersedia melalui: < https://ojs.uajy.ac.id/index.php/IJIS/article/ view/1723> [Diakses 1 April 2021] 